\title{
VISUALIZAÇÕES DEINTERAÇÕES ENTRE O DIREITO EA TEORIA FEMINISTA DE GÊNERO A PARTIR DE ASPECTOS CONTROVERSOS DA LEI 11.340/2006*
}

\author{
Kamylla da Silva Bezerra, ${ }^{\dagger}$ \\ Félix Araújo Neto:
}

RESUMO: A violência doméstica contra a mulher foi conceituada pela Lei 11.340/2006 como qualquer ação ou omissão baseada no gênero que cause morte, lesão, sofrimento físico, sexual, psicológico e dano moral ou patrimonial. Com a entrada dessa lei em vigor,surgiram inúmeras dúvidas quanto à sua incidência, algumas relacionadas à utilização do conceito de gênero. Assim, este artigo tem por objetivo analisar a interação do direito com as teorias feministas, mais especificamente aquelas que se utilizam dos conceitos de gênero para explicar fenômenos como a violência doméstica contra a mulher. Assim, para alcançar a finalidade deste trabalho foram utilizados os seguintes procedimentos práticos metodológicos: levantamento documental e levantamento bibliográfico. Como resultado pode-se observar que a teoria feminista de gênero trouxe significativos avanços no que tange aos direitos das mulheres e de grupos considerados vulneráveis durante $\mathrm{o}$ decorrer da história, se caracterizando, assim, como uma teoria crítica do direito. Ademais, pode-se vislumbrar o início de interesse e aceitação quanto à utilização do conceito de gênero das teorias feministas no judiciário brasileiro, ao apontar a existência de decisões judiciais que fazem emprego desta teoria em suas fundamentações.

PALAVRAS-CHAVE: teoria feminista; Lei Maria da Penha; controvérsias judiciais.

\section{VIEWS FROM INTERACTIONS BETWEEN THE RIGHT AND FEMINIST THEORY OF GENDER ISSUES FROM CONTROVERSIAL LAW 11.340/2006}

\begin{abstract}
Domestic violence against women was conceptualized by Law 11.340/2006 as any action or omission based on gender which causes death, injury, suffering physical, sexual, psychological and moral or property damages. With this law in place there were emerged many doubts as to its incidence, some related to use of gender concept. Thus, this article aims to analyze the law interaction with feminist theories, more specifically those that use gender

\footnotetext{
*Artigo recebido em 03/09/2013 e aprovado em 11/05/2014

†raduanda do curso de bacharelado em Direito pela Universidade Estadual da Paraíba - UEPB. Pesquisador bolsista de Iniciação Científica do CNPq. Email: mylla_74@hotmail.com. Contato: (83) 9925-2215

* Professor Titular do Centro de Ciências Jurídicas da Universidade Estadual da Paraíba - UEPB. Doutor em Direito Penal e Política Criminal pela Universidade de Granada - UGR.Email: félixaraujoneto@hotmail.com.
} 
concepts to explain phenomena such as domestic violence against women. Thus, to achieve this work purpose we used the following practical methodological procedures: documental and bibliographic survey. As a result it can be seen that the women's genre theory has brought significant advancements regarding the women rights and vulnerable groups considered during the course of history, been characterized as a critical law theory. Moreover, we can glimpse the beginning of the interest and acceptance about the use of the gender concept of feminist theories in the Brazilian judiciary, pointing to the existence of judicial decisions that make use of this theory in their foundations.

KEY WORDS: feminist teory; Maria da Penha Law; judicial controversies.

\section{INTRODUÇÃO}

A teoria feminista do direito que trata, entre outras questões, daquelas relacionadas ao gênero, tem sido ignorada pelos juristas brasileiros. Apesar de não serem poucas as organizações e entidades que trabalham com o tema dos direitos das mulheres no país, e realizam intervenções práticas, quando se parte para a reflexão teórica desses temas, a carência é quase que absoluta. Tal fato se dá pela existência de uma desconfiança mútua, tanto dos juristas para com as feministas, como vice e versa. Assim, é bem verdade que, para algumas feministas, os estudos jurídicos perpetuam uma representação do direito como técnica de controle social neutra, universal, abstrata, quando, na verdade, o direito já representa um ponto de vista previamente sexualizado (OLSEN, 2000). Já aos olhos dos juristas, a teoria feminista parece ensejar mais "uma teoria contra o direito do que propriamente uma teoria do direito" (REVILLARD \& LEMPEN, 2008).

Apesar da desconfiança e falta de interesse mútuos, fato é que as teorias feministas já exercem grande influência no meio jurídico brasileiro, a exemplo das inúmeras modificações realizadas em leis que foram conquistadas a partir da reivindicação feminista. Assim, com uma legislação que perpetuava uma discriminação negativa no que tange às questões de gênero, era de extrema relevância que fossem propostas novas saídas para que as mulheres pudessem, de fato, obter a igualdade de gênero. Convém citar como exemplo as seguintes modificações: questionamento da separação público/privado com a consequente reivindicação de interferência da justiça na esfera doméstica; o Código Penal que até o ano de 2005 trazia o conceito de "mulher honesta", para a identificação da conduta moral e sexual considerada irrepreensível, característica indispensável para a proteção legal em determinados crimes sexuais; e ainda no Código Penal, era possível, até o ano de 2005, que caso o 
estuprador casasse com sua vítima, o mesmo não seria condenado por seu crime, em face da "reparação do dano aos costumes".

Dessa forma, a lei 11.340/2006 foi instituída, segundo Bianchini (2013), com o objetivo de coibir e prevenir a violência de gênero no âmbito doméstico, familiar ou de uma relação íntima de afeto. Dessa forma, fazendo uso do conceito de gênero,essa lei concretizou a relação entre as teorias feminista de gênero e direito, cabendo aos juristas o estudo dessa abordagem, tendo em vista sua manifestação em âmbito jurídico.

Os estudos de gênero surgiram no século $\mathrm{XX}$, tendo por objetivo problematizar os diferentes valores culturalmente atribuídos às mulheres e aos homens, que definem os comportamentos e expectativas sobre o papel de cada um dos gêneros em nossa sociedade. Assim, sucintamente, Saffioti (2004) conceitua gênero como a construção social do masculino e do feminino.

No que tange à correlação entre gênero/direito, Rêgo et.all (2012) explica que longe de ser apenas um detalhe de aspecto normativo, o conceito de gênero deve assumir uma postura nevrálgica em qualquer leitura que seja feita da lei 11.340/2006. Da mesma forma, acrescenta ser elementar que a utilização desse conceito pela referida lei não está delimitada pelo sexo geneticamente definido, não tendo vinculação fisiológica com o corpo do individuo. Assim, para além do dado biológico que define o sexo (registro sexual homem ou mulher), o gênero é concebido como o sexo socialmente construído (ANDRADE, 2004).

Logo, se verifica que gênero trata-se de um elemento normativo extrajurídico que se apresenta de forma crucial para abordagem dos institutos jurídicos que tratam dos direitos das mulheres. Igualmente, parte da doutrina tem setorizado o direito penal a partir de uma abertura para um específico ramo chamado direito penal de gênero, com a tipificação do crime de gênero:

Não se trata, portanto, de qualquer conduta lesiva contra uma mulher. Para ser crime previsto na nova Lei, é necessário que a conduta seja baseada no gênero. A ação ou omissão que não for baseada no gênero não tem previsão típica na Lei Maria da Penha. A violência doméstica familiar ou em qualquer relação íntima de afeto contra uma mulher,que não for baseada no gênero, realiza tipos penais comuns e não está abrangida pela nova Lei. Assim, odireito penal de gênero é formado pelo estudo dos tipos penais que têm um elemento 
específico que os define como crime de gênero, ou seja, conduta baseada no gênero" (SILVA JUNIOR, 2012).

Portanto, o estudo que relaciona a teoria feminista e que envolve a utilização dos conceitos de gênero, com o direito acaba por criar uma instigante teoria crítica: teoria feminista crítica do direito. Rabenhorst (2010) afirma que essas abordagens proporcionam uma reflexão produtiva sobre os limites do formalismo jurídico e da teoria liberal que the oferece sustentação, apontando para um projeto concreto de transformação do direito.

\section{Os propósitos da teoria feminista ao longo do tempo}

Cabe inicialmente esclarecer que falar em feminismo no singular, como foi feito até agora, é incorrer em grande equívoco. Tal fato de justifica por se estar diante de um pensamento que não se caracteriza de forma singular ou de uma prática política homogênea. A história do feminismo abarca uma série de teorias que apontam sua herança filosófica comum no liberalismo do séc. XIX.

Na perspectiva de Nye (1995), pode-se destacar algumas das teorias feministas mais importantes a nível histórico e que explicam a evolução desse movimento durante as revoluções e modificações sociais. A saber, tem-se os chamados: feminismo liberal; feminismo marxista; feminismo existencialista e, finalmente, o feminismo dos estruturalistas da linguagem.

As primeiras justificações sistemáticas dos direitos das mulheres foram tomadas de empréstimo à teoria liberal e democrática. A panaceia democrática do voto era o foco da luta feminista. John Locke, Jean-Jacques Rousseau e os utilitaristas modelaram um mundo no qual os homens podiam ser livres e iguais e uma sociedade onde estes determinariam seus próprios destinos. No entanto, essas ideias jamais pretendiam aplicar-se às mulheres.

As reformas democráticas da Revolução Francesa foram teorizadas como só beneficiando as mulheres indiretamente: como são dependentes dos homens, logo, estarão emmelhor situação porque os homens estarão em melhor situação. 
$\mathrm{Na}$ primeira grande onda de feminismo do séc. XIX, a principal questão era o sufrágio. Outras questões (direito de propriedade, reforma do casamento e liberdade sexual) eram discutidas, mas o foco era do voto como modo correto e mais prático para as mulheres atingirem suas metas, acreditando que quando estas estivessem aptas a votar, elas o fariam em favor de uma legislação que corrigiria as injustiças praticadas (NYE, 1995).

Assim, a primeira defesa sistemática dos direitos das mulheres veio de John Stuart Mill e Harriet Taylor. Mill era utilitarista na tradição bethamista, membro do grupo Radical Filosófico, e após encontrar-se com Harriet aproximou-se cada vez mais dos Radicais Unitaristas. Estes eram mais literários, mais radicais e mais libertários que os utilitaristas, sobretudo em questões de família e sexualidade.

Com argumentos por uma sociedade na qual os interesses de todos os homens fossem considerados e, ao mesmo tempo, na qual os direitos individuais de cada homem fossem protegidos, Mill e Taylor descobriram a justificação para uma correspondente revolução feminista. Seus argumentos formaram agenda para os anos seguintes de feminismo liberal.

O utilitarismo de Bentham (1979) serviu de base para a construção teórica de Mill, na qual se entendia que as coisas humanas eram governadas por dois senhores soberanos: o prazer e o sofrimento. A partir da perspectiva benthamista pretende-se que a sociedade nada mais é do que um punhado de indivíduos que procuram o prazer e evitam o sofrimento, e uma sociedade justa é aquela na qual se produz o máximo de prazer e o mínimo de sofrimento. Assim, toda lei ou ação que cause a máxima felicidade e o mínimo sofrimento é justa. Dessa forma, são esclarecidos dois princípios importantes da reforma política: nenhum prazer deve ser superior a qualquer outro, exceto quanto à quantidade, e cada pessoa deve ser considerada o melhor juiz do seu próprio prazer.

Como se disse, o voto feminino era o mecanismo pelo qual as outras reformas seriam conquistadas e os interesses das mulheres alcançados, assim, reivindicava-se que o voto deveria ser para todos, e todos não podia significar a metade masculina. Os argumentos de Bentham (1979) se aplicam nesse contexto: as mulheres têm interesses, sofrem, desfrutam prazer. E em que base não seriam elas o melhor juiz de como esses interesses devam ser atendidos? 
No entanto, o utilitarismo de Bentham tinha uma fragilidade, como observara Mill (1961). E se as mulheres não quisessem votar, ter empregos, ser educadas? Em meados do séc. XIX a maioria das mulheres não apoiava o sufrágio feminino. Assim, se a avaliação que a mulher faz do seu próprio prazer não é confiável, então o utilitarismo que servia de base para a teoria liberal, por si só, é inadequado para a defesa dos direitos das mulheres.

Já em 1900, outro tipo de feminista existia: a mulher que trabalhava. É o caso da feminista socialista Flora Tristan, que podia falar por experiência própria de miséria, más condições de trabalho e do desespero da prostituição. Podia-se também comparar a Emma Goldman, nascida na Rússia em 1869 em uma família pobre. Essas mulheres não tinham quaisquer das vantagens da posição da classe ou riqueza das feministas liberais.

Nessa etapa acreditava-se que o antídoto para a opressão das mulheres não era a legislação, mas uma organização de trabalhadores. As feministas não deviam tentar descobrir nas estruturas socioeconômicas existentes os meios legais de defender os interesses das mulheres, mas trabalhar para destruir aquelas estruturas. Argumentava-se que a opressão das mulheres era só superficialmente causada pelas leis ou falta delas e que, no entanto, a exploração de uma classe por outra se encontrava na base da essência do capitalismo (GOLDMAN,1970). Nascia, assim, o feminismo marxista.

Seguidor de Friedrich Engels, o social-democrata August Bebel influenciou feministas como Alexandra Kollatai e Clara Zektin, com seu livro "Womanundersocialims". Bebel se empenhava em tentar convencer seus companheiros socialistas de que as mulheres trabalhadoras deviam ser iguais aos homens no Estado socialista.

Bebel se inspirava na genealogia de Engels (1884) do sexismo: a familia monogâmica, chefiada pelo homem, advém da propriedade privada ${ }^{\S}$. Os defeitos das mulheres seriam advindos de sua situação degradada e podiam ser corrigidos na nova sociedade socialista (BEBEL, 1904). Assim, o autor pretendia que, com o alvorecer do socialismo, as mulheres teriam direitos trabalhistas iguais aos dos homens, seriam educadas e teriam participação à semelhança masculina.

\footnotetext{
§Engels mostrava que o sexismo não era universal, visto que houve tempo que a terra era possuída comunalmente, quando a herança era através da mãe, quando o trabalho da mulher tinha mesmo valor que o dos homens.A família, tal qual como conhecemos, nasceu com a propriedade privada, que também causa "a derrota histórica mundial do sexo feminino".
} 
Entretanto, a teoria marxista deixa de lado as questões de família e sexo por se tratarem de assuntos privados e nada terem a ver com a produção. A sugestão de que novas formas sexuais e familiares pudessem ser criadas pelas mulheres enfrenta desaprovação, visto que tais discussões não eram consistentes com o modelo sindicalista de organização dos trabalhadores, sendo tratadas como atividades não produtivas (NYE, 1995).

Desse modo, embora nessas análises a ideologia ou o discurso estejam relacionados com estruturas econômicas, as categorias analíticas feministas devem pouco à teoria marxista, visto que esta não oferece uma explanação histórica da opressão de mulheres ou um modo de situar a opressão em realidades materiais específicas, nem um programa de ação. Não era possível, assim, analisar a reprodução da personalidade humana na família porque na teoria marxista não são as personalidades responsáveis pela mudança social.

Ademais, existe uma lacuna na exposição de Friedrich Engels sobre o momento em que a estirpe feminina foi derrubada. Se as relações de propriedade é que devem ser culpadas, para que estas não sejam um simples demônio machista, como esclarece Nye (1995), deve-se explicar também o porquê de as relações de propriedade terem sido constituídas em primeiro lugar contra a comunidade, e especificamente entre os homens. Sem essas explicações as ligações entre o sexismo e relações produtivas não prevalecem, e a produção assume uma precedência automática que assegura a correção do sexismo independente da real situação das mulheres. Assim, não tendo explicado o fenômeno em questão, o marxismo é incapaz de elaborar um programa adequado para a libertação das mulheres.

Por conseguinte, surge Beauvoir (1949) tentando repensar as condições de existência feminina num contexto onde não sobra absolutos, nenhuma certeza. Deus foi destronado pela razão científica, e agora a religião não tinha nem mesmo a validade subjetiva de outrora. Ao mesmo tempo, a batalha pela igualdade jurídica foi amplamente vencida; as mulheres votavam, podiam ter propriedade, eram juridicamente iguais no casamento e a sociedade civil parecia aceitá-las como membros atuantes.

Assim, o enfoque representado por Simone de Beauvoir em $O$ segundo sexo, não tinha como base ideológica a economia ou a política, mas a filosofia. $\mathrm{O}$ existencialismo seria a perspectiva pela qual se teriam condições de compreender a situação das mulheres. E isto será possível porque trata de indivíduos humanos, e não de coletividades mudas como 
fazia a teoria marxista. Assim, um feminismo existencialista poderia oferecer um estudo tanto da opressão das mulheres como de sua emancipação.

Qualquer exame que Beauvoir faz em seu livro, envolve o existencialismo. Para a autora, a luta de classes não é por si explicativa, pelo contrário, a apropriação masculina da propriedade privada só é inteligível como projeto do individuo de autoafirmação e transcendência. A autora afirma que a alteridade da mulher é anterior às relações de propriedade e que esta se faz necessária para obter o entendimento do por que as relações de propriedade assumem as formas que têm.

Da perspectiva existencialista pode-se dar uma exposição alternativa das origens do sexismo que responde à questão de por que não foram as mulheres a firmar direitos de propriedade. Isso não se deve, dizia Beauvoir (1949), a qualquer tipo de essência feminina, mas à situação da mulher.

Assim, se explica que a inferioridade da mulher não é natural, fisiológica ou psicológica. A mulher não tem essência, tanto quanto nenhum ser humano tem. A opressão das mulheres fica ainda mais poderosa naquilo em que é mascarada por trás da natureza, por trás da crença de que o destino das mulheres é a passividade, pois não se pode rebelar contra a natureza. Beauvoir (1949) não negava a existência do feminino e do masculino, mas afirmava que a aceitação dessas categorias (institucionalização na familia e no trabalho) é que perpetuavam a inferioridade das mulheres.

De acordo com Nye (1995), do existencialismo de Beauvoir surge o feminismo radical, que herda uma fragilidade teórica que a torna inevitável na prática. Segundo a autora, em primeiro lugar, o poder como artifício teórico é por demais rústico para explicar a complexidade da interação humana. Mesmo que fosse verdade que os homens precisem representar o papel opressor, como afirmava Beauvoir (1949), as origens sociais e ideológicas dessa necessidade devem ser examinadas. A teoria feminista radical não consegue explicar porque desde o início da historia existencialista foram os homens que se afirmaram. Beauvoir (1949) recorreu ao determinismo biológico para tal esclarecimento: as mulheres devem dar à luz e por isso estão em desvantagem, o que acaba por enfraquecer tal linha de abordagem pela falta de inovação.

Entretanto, surge a perspectiva de que não é a "natureza" ou qualquer realidade fisica que determinaria a posição inferior das mulheres, mas uma diferença de "pensamento", 
como afirmava Lacan (1982), acrescentando que a única diferença real era que as mulheres não sabem o que estão dizendo.

Essa linha de pensamento, pertencente aos estruturalistas da linguagem, observa que são comuns os pares de palavras semelhantes ao significado, mas diferentes em relação ao gênero. Era de se esperar que o conteúdo semântico dessas palavras não se alterasse, e que apenas o gênero mudasse, no entanto, não é isso que acontece. Nye (1995) exemplifica as palavras "solteirona" e "solteirão", onde a primeira nada tem de aspecto satisfeito e requintado da segunda, indicando mais fracasso e inatratividade.

Assim, segundo esta abordagem, fica a impressão de que não existem palavras neutras com que se possa tentar indicar uma relação masculino/feminino na qual a mulher seja dominante ou igual. Acredita-se que poder e feminilidade são contraditórios, que o componente semântico da dominância é masculinizado e que a inferioridade das mulheres é codificada na linguagem.

Nesse diapasão, a força semântica dos sufixos femininos é semelhante na vinculação de feminilidade e impotência. No aspecto da exemplificação, há herói e heroína, garçons e garçonetes, sacerdote e sacerdotisa, poetas e poetisas. A transição sexual é indicada na força diminutiva do sufixo acrescentado.

Nye (1995) aponta que os títulos são mais uma maneira de denotar a diferença masculino/feminino codificada na linguagem. Cada indivíduo é tratado como masculino (senhor) ou feminino (senhorita e senhora). Entretanto, a diferença é assimétrica: o estado civil da mulher é codificado, ao passo que o do homem não. Isto reflete a expectativa de que a identidade da mulher depende da do seu marido.

O exemplo mais frequentemente criticado do sexismo linguístico é o emprego genérico de "homem". No caso, persiste a valorização do masculino, não tanto a codificação da inferioridade do feminino. "Evolução do homem", "direito do homem" e expressões afins indicam que o ser propriamente humano é masculino.

Dessa forma, esses e outros exemplos fizeram com que, na perspectiva das linguísticas feministas, houvesse a conclusão de que a diferença de sexos encontra-se 
embutida no vocabulário disponível, tornando improvável que, no atual estado, essa linguagem possa ser um veículo de expressão das mulheres.

\section{Dos questionamentos à utilização do conceito de gênero em âmbito jurídico}

Logo da sua entrada em vigência, a Lei ${ }^{\circ}$ 11.340/2006 suscitou divergências quanto sua constitucionalidade, ficando esclarecido que a referida lei fere o princípio da isonomia, na medida em que estabelece uma desigualdade somente em função do sexo. Ademais, a mulher vítima seria beneficiada por melhores mecanismos de proteção e de punição contra o agressor. Já o homem não disporia de tais instrumentos quando fosse vítima da violência doméstica ou familiar. Este era o entendimento de autores como Santin (2007) e Campos (2007). Dessa forma decidiu aSegunda Turma Criminal do Tribunal de Justiça do Mato Grosso do Sul (TJMS):

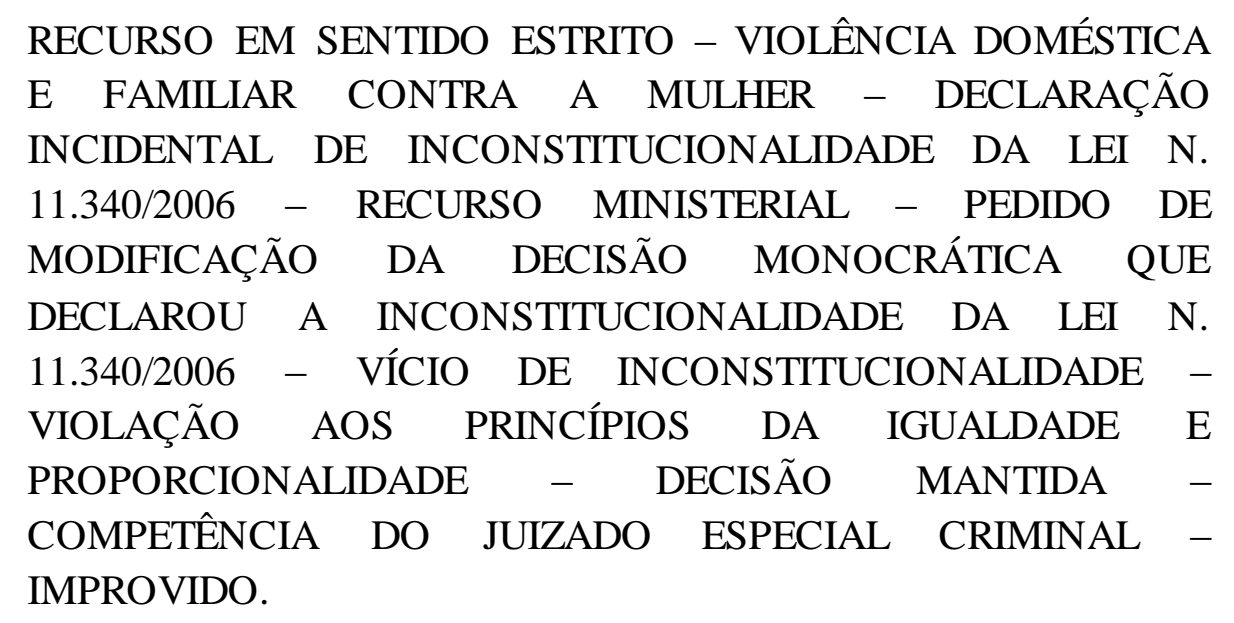

A Lei n. 11.340/2006 (Lei Maria da Penha) está contaminada por vício de inconstitucionalidade, visto que não atende a um dos objetivos da República Federativa do Brasil (art. 30, IV da CF), bem como por infringir os princípios da igualdade e da proporcionalidade (art. $5^{\circ}$, II e XLVI, $2^{\text {a }}$ parte, respectivamente). Assim, provê-se o recurso ministerial, a fim de manter a decisão que declarou a inconstitucionalidade da Lei n. 11.340/2006, determinandose a competência do Juizado Especial Criminal para processar e julgar o feito. (grifou-se)

Entretanto, fica claro o equívoco realizado diante da ausência de conhecimento acerca do conceito de gênero, onde se relacionam não os aspectos fisiológicos do sexo, mas os 
sociológicos. Assim, no ano de 2012, o Superior Tribunal Federal alegou procedente a Ação Declaratória de Constitucionalidade 19 (ADC 19), onde, por unanimidade, declarou a constitucionalidade dos artigos $1^{\circ}$, 33 e 41 da Lein $^{\circ} 11.340 / 2006$, propiciando uma interpretação judicial uniforme dos dispositivos contidos nesta lei. Assim, está afastada qualquer dúvida quanto à constitucionalidade da Lei Maria da Penha.

Outra questão suscitada a partir das previsões da Lei Maria da Penha se constitui no questionamento sobre a possibilidade de este instrumento legal ser aplicado em virtude da proteção do homem. A questão deve ser analisada, mais uma vez, utilizando-se o conceito de gênero, ou seja, vislumbrando não os aspectos fisiológicos do sexo, mas sociais.

No que tange à violência da mulher contra o cônjuge, companheiro ou namorado, é fato que tal agressão distingue-se, e muito, da praticada pelo homem, seja em virtude da menor intensidade, finalidade, motivos ou contextos. Um dos aspectos mais importantes da violência doméstica de gênero diz respeito à "sensação de temor contínuo a uma ameaça onipresente e onipotente" (BIANCHINI,2013), o que possibilita medidas mais enérgicas e efetivas realizadas exclusivamente para proteger o gênero feminino em situação de violência doméstica. Assim, Bianchini (2013) esclarece que a aplicação da Lei Maria da Penha ao homem vítima de violência praticada em contexto doméstico é indevida, visto a não incidência dos principais fundamentos e especificidades da violência de gênero para aplicação da lei. Dessa forma vem sendo decidido em diversos Tribunais brasileiros, entre os quais o TJPB e TJMG:

CONFLITO NEGATIVO DE COMPETÊNCIA. Vara Criminal versus Juizado Especial Criminal. Violência doméstica e familiar. Crime, em tese, de lesão corporal leve. Vitima do sexo masculino. Alteração da redação do $\S 9^{\circ}$ do artigo 129 do Código Penal. Pena abstrata superior a 02 (dois) anos. Inaplicabilidade da Lei n. ${ }^{\circ}$ 11.340/06. Lei Especial que ampara, exclusivamente, a violência praticada contra a mulher no âmbito doméstico e familiar. Competência do Juízo Comum. (TJPB. Processo nº.2011.0037981/0011. Rel. Dr. Onaldo Rocha de Queiroga. Data do julgamento: 27/03/2012. Data da publicação: 02/03/2012).

PROCESSO PENAL - CONFLITO DE JURISDIÇÃO - LESÃO CORPORAL - ÂMBITO DOMÉSTICO OU FAMILIAR - PRÁTICA CONTRA HOMEM - LEI MARIA DA PENHA INAPLICABILIDADE. DECLARADA A COMPETÊNCIA DA 
JUÍZA SUSCITANTE. De acordo com o disposto no art. $1^{\circ}$, da Lei ${ }^{\circ}$ 11.340/06, o referido diploma legal visa coibir e prevenir a violência doméstica e familiar contra a mulher. Logo, tratando-se a vítima de homem, não há como se aplicar a mencionada lei. (TJMG. Processo n. ${ }^{\circ}$ 0610666-28.2010.8.13.0000. Relator: Des. Herbert Carneiro. Data do julgamento: 12.01.2011. Data da publicação: 27.01.2011).

Por outro lado, Bianchini (2013) esclarece que a aplicação da Lei Maria da Penha para vítima transexual masculina foi reconhecida na decisão oriunda da $1^{\text {a }}$ Vara Criminal da Comarca de Anápolis (Proc. 201.103.873.908, TJGO), trazendo como motivações: a realização da cirurgia de redesignação sexual torna a pessoa do sexo feminino, no que tange o seu "sexo social"; o gênero é construído no decorrer da vida e se refere ao estado psicológico, de forma que o transexual não se confunde com homossexual, pois este não nega seu sexo. Bianchini (2013) acrescenta, ainda, que para o amparo da lei, não se faz necessária a mudança de nome, com alteração do registro de identidade.

No que tange às relações homoafetivas, ressalta-se que estas foram englobadas no conceito de família da Lei 11.340/2006, visto a determinação de seu art. $5^{\circ}$ de que "as relações pessoais enunciadas neste artigo independem de orientação sexual", assim como o seu art. $2^{\circ}$ preceitua que

“(...) Toda mulher, independente de (...) orientação sexual, (...) goza dos direitos fundamentais inerentes à pessoa humana, sendo-lhes asseguradas as oportunidades e facilidades para viver sem violência, preservar sua saúde física e mental e seu aperfeiçoamento moral, intelectual e social". (BRASIL, 2006)

Da mesma forma, Rodolpho (2009) assevera:

“Com advento da Lei Federal no 11.340, que entrou em vigor em agosto de 2006, temos um avanço positivo em relação ao novo conceito de entidade familiar. Esta nova lei, conhecida como “Lei Maria da Penha", criou mecanismos para coibir e prevenir a violência doméstica e familiar contra a mulher. Mas, não só regulamentou a violência no âmbito doméstico como trouxe uma carga ideológica inovadora, pois permitiu uma interpretação de 
reconhecimento da entidade familiar entre pessoas do mesmo sexo. [...] Hoje, a família é entendida sob uma nova visão, como um núcleo de afetividade, portanto, o afeto não está restrito às uniões heterossexuais. Desse modo, os relacionamentos de pessoas do mesmo sexo, que mantêm uma relação baseada na afetividade, devem ter a merecida pretensão e reconhecimento previstos na Constituição Federal'. (grifou-se)

Assim, vítimas de violência doméstica oriundas de relações homoafetivas, sejam lésbicas ou homossexuais, possuem o respaldo e proteção dos institutos da Lei $n^{\circ}$ 11.340/2006, devido à utilização e correto entendimento do conceito de gênero acerca da caracterização da incidência dessa violência regulamentada pela lei. E, mais uma vez, dessa forma vem decidindo os tribunais pátrios:

RELACIONAMENTO HOMOAFETIVO ENTRE MULHERES. LESÕES CORPORAIS. LEI MARIA DA PENHA. APLICABILIDADE. Enquanto em relação ao sujeito passivo a Lei elegeu apenas a mulher, no polo ativo das condutas por ela compreendidas encontram-se homens ou mulheres que pratiquem atos de violência doméstica e familiar contra mulheres. Dessa forma, se mulher com relacionamento homoafetivo sofre lesões corporais praticadas por sua companheira, no âmbito doméstico e familiar, aplica-se a Lei Maria da Penha em todos os seus termos. (TJMG, RSE 7918639-66.2007.8.13.0024, 7 ${ }^{\mathrm{a}}$ C. Crim., Rel. Des. Duarte de Paula, p. 17/06/2011)

CONFLITO DE COMPETÊNCIA. VIOLÊNCIA DOMÉSTICA. RELAÇÕES HOMOAFETIVAS. OFENDIDA MULHER. GÊNERO INDEPENDE DA ORIENTAÇÃO SEXUAL. COMPETÊNCIA DA VARA ESPECIALIZADA. 1- A Lei $n^{\circ}$ 11.340/06 destina-se a proteger a mulher de violência doméstica, não importa sua opção sexual, nem que envolva relações homoafetivas e a agressora seja outra mulher. 2- $\mathrm{O}$ artigo $5^{\circ}$ da Lei estabelece como âmbito de incidência a proteção da mulher na unidade doméstica, abrangendo os indivíduos que nela convivem ou qualquer relação de afeto, vínculo familiar, mesmo que não mais coabitem independente da orientação sexual. A Lei não é limitada pelo gênero do agressor, sua finalidade é sempre proteger a mulher, independente de opção sexual (parágrafo 
único do artigo $5^{\circ}$ ). 3- Competente a Vara de Violência Doméstica exercida na Comarca pela Vara de Familia. Conflito procedente. (TJRS, Conf. Jurisd. 70036742047, 3 $3^{\text {a }}$ C. Crim., Rel. Desa. Elba Aparecida Nicolli Bastos, j. 22/07/2010).

Cumpre esclarecer que, no que diz respeito às relações homossexuais entre homens existem algumas especificidades quando tratamos da incidência da Lei Maria da Penha. Parodi \& Gama (2009) asseveram que, de fato a analogia autoriza a proteção do homem quando vítima de violência doméstica desde que este conviva com outro homem formando um casal homossexual. As decisões dos principais tribunais tendem a seguir no mesmo sentido, autorizando a aplicação com base no princípio da isonomia. Segundo o entendimento do TJRS, de acordo com o Juiz de Direito Osmar de Aguiar Pacheco, em decisão referente à temática, o art. $5^{\circ}$ da Constituição Federal brasileira prevê que, em situações iguais, as garantias legais valem para todos, acrescentando que "todo aquele que é vítima de violência, ainda mais a do tipo doméstica, merece a proteção da lei, mesmo que pertença ao sexo masculino". Seguindo o mesmo entendimento, o TJRJ decidiu em 2011 (processo $\mathrm{n}^{\circ}$ 0093306-35.2011.8.19.0001), a devida aplicação de medidas protetivas previstas na Lei 11.340/2006 em caso de agressão entre homens que formavam um casal homossexual, a qual segundo o Juiz de Direito Alcides da Fonseca Neto da $11^{\mathrm{a}}$ Vara Criminal do Rio de Janeiro:

"A especial proteção destinada à mulher pode e deve ser estendida ao homem naqueles casos em que ele também é vítima de violência doméstica e familiar, eis que no caso em exame a relação homoafetiva entre o réu e o ofendido, isto é, entre dois homens, também requer a imposição de medidas protetivas de urgência, até mesmo para que seja respeitado o princípio constitucional da isonomia".

Cumpre salientar que a aplicação da Lei Maria da Penha em casos de violência doméstica entre casais homossexuais masculinos é devida e que sua fundamentação também está relacionada à utilização da teoria de gênero na conceituação de violência doméstica dada pela Lei Maria da Penha. Segundo Swain (2001) os homens gays são definidos em termos de ausência de suas masculinidades, apresentando certa identificação com o feminino, no momento em que o indivíduo é dominado por outro homem como se fora uma mulher. Por outro lado, Torrão Filho (2004) assevera que em muitos países da América Latina a 
homossexualidade masculina é vista sob uma dupla moral, sendo ativos e passivos encarados de maneira diferente. Assim, podem existir relações homossexuais em que um indivíduo assuma papel vulnerável, submisso, identificado, geralmente, pela passividade inerente à construção social do papel feminino nas relações.

Nunan (2004) esclarece que, no caso dos homossexuais, as dificuldades de se conviver e abandonar uma relação violência podem ser as mesmas ou até piores do que em uma relação heterossexual. A autora indica que assumir uma relação violenta significa, na maioria dos casos, revelar sua orientação sexual para uma série de indivíduos (polícia, psicólogos, médico, familia), atitude extremamente difícil de ser tomada, visto a existência inegável de preconceito por parte de parcela da sociedade diante das relações homoafetivas. Por outro lado, ao contrário dos casais heterossexuais, gays e lésbicas tendem a estar mais alienados de suas familias de origem devido justamente ao preconceito associado à sua orientação sexual, fazendo, assim, com que deem ainda mais valor aos seus relacionamentos e estes podem ser suas únicas fontes de suporte emocional. Dessa forma, Nunan (2004) classifica o rompimento com o parceiro como um dos eventos mais estressantes para os homossexuais.

Dito isso, é inegável a correta aplicação dos institutos da Lei Maria da Penha em casos de violência doméstica no seio de relações homossexuais, mesmo quando se lida com uma parceria masculina, tendo sempre como fundamento a relação entre os gêneros, e lembrando que esta se refere a uma construção social dos papéis do homem e da mulher, e não apenas às questões fisiológicas (macho/fêmea).

Portanto, é possível visualizar que as relações entre gênero e a ciência jurídica estão cada vez mais acentuadas, seja pela implementação de leis que tragam em seu conteúdo estas afinidades ou por decisões dos Tribunais Superiores e Estaduais de todo o país que buscam seu fundamento nesta teoria. A Lei $\mathrm{n}^{\mathrm{o}}$ 11.340/2006 realizou grandes inovações no que diz respeito à violência de gênero, além de trazer um novo conceito de família, ao asseverar que as relações protegidas por seu âmbito independem de orientação sexual, servindo, mais tarde, entre outras coisas, para basilar o entendimento do Supremo Tribunal Federal de que as uniões homoafetivas também constituem entidade familiar (ADI 4277e ADPF 132).

\section{CONSIDERAÇÕES FINAIS}


O ponto de vista lúcido sobre a real função do direito ainda é incipiente no campo dos estudos jurídicos, persistindo a visão de que essa ciência se baseia em um discurso regulador neutro, voltado para sujeitos abstratos e homogeneizados. Por outro lado, as inovações e contribuições indicadas pela crítica feminista ao direito não consistiram em apenas introduzir teorias ou conceitos em seu objeto de estudo, mas, sobretudo trouxe à reflexão temas que antes eram marginalizados, enfatizando, assim matérias que haviam sido deixadas no esquecimento.

Com o intuito de eliminar a condição de subordinação das mulheres em diversos níveis sociais, a teoria feminista contribui incisivamente para o desenvolvimento de políticas tanto sociais quanto jurídicas que visem à proteção e emancipação do gênero feminino em meio à sociedade. Dessa forma, as interações entre a ciência jurídica e as teorias de gênero e o feminismo acabam por desmistificar julgamentos fundados em conceitos préconcebidos, construídos socialmente, e que setores conservadores da sociedade insistem em perpetuar.

Portanto, é de extraordinária importância que antes que se inicie o estudo dos institutos e aspectos da Lei Maria da Penha compreendam-se as relações de gênero. Ademais, essa abordagem que possibilita a interlocução entre gênero e direito se constitui em condição para uma prática jurídica crítica, sendo esta extremamente necessária em meio à realidade de nosso país.

\section{REFERÊNCIAS}

ANDRADE, V. R. P. A Soberania Patriarcal: o Sistema de Justiça Criminal no Tratamento da Violência Sexual Contra a Mulher. In: Revista Brasileira de Ciências Criminais, n. 48, p. 260/290, maio/jun. 2004.

BEAUVOIR, S. O Segundo sexo. São Paulo: Difusão Européia do livro. 1970.

BEBEL, A. Woman under socialism. Nova York: Labor Express, 1904.

BETHAM, J. An introduction to the principies of moral and legislation, Claredon Press, Oxford.1976. 
BIANCHINI, A. Lei 11.340/2006: aspectos assistenciais, protetivos e criminais da violência de gênero. $1^{\mathrm{a}}$ Ed. São Paulo: Saraiva, 2013.

CAMPOS, R. T. Aspectos Constitucionais e Penais Significativos da Lei Maria da Penha. Disponível em: <>http://www.blogdolfg.com.br<>. Acesso em: 14 de Julho de 2013.

ENGELS, F. El origen de la Familia, de la Propriedad Privada y del Estado.Madrid: Mestas Ediciones, 1884.

GOLDMAN, E.The traffic in Woman and others essays on feminism. Washington: Ed. Times changes Press, 1970.

LACAN, J. Feminine Sexuality. Ed. MITCHELL, J. ROSE, J. Trad. ROSE, J. Inglaterra: Pitman Press Beaconsfield, 1982.

MILL, J. S. Principies of political economy.Nova York: Kelley, 1961.

NEY, A. Teoria feminista e as filosofias do homem. Rio de Janeiro: Rosa dos tempos, 1995.

NUNAN, A. Violência doméstica entre casais homossexuais: o segundo armário? PSICO, v. 35, n. 1, 2004. P. 69-78.

OLSEN, F. El seco delderecho. In: RUIZ, A. E. C. Identidad feminina y dicurso jurídico. Buenos Aires: Bilos, 2000, p. 14.

RABENHORST, E. R. Encontrando a teoria feminista do direito. Prima Facie, João Pessoa, v. 9, n. 17,2010, p. $8-24$.

REGO, N. M. M, Et.all. Lei Maria da Penha: O conceito de gênero como núcleo interpretativo.In: AMMA Associação dos Magistrados do Maranhão. Disponível em:<> http://www.amma.com.br/artigos 2,3464, ,lei-maria-da-penha-o-conceito-de-generocomo-nucleo-interpretativo<>. São Luís, Maranhão, Brasil. Julho de 2012. Acessado em: 14 de Julho de 2013.

REVILLARD, A. LEMPEN, K. "A la recherché d'une analyse feminist du droit dans les é crits francophones”. Nouvelles Questions Féministes, vol 28, n. 2, 2008, p. 6.

RODOLPHO, J. Uniões homoafetivas e Lei Maria da Penha. Disponível em: $<>$ http://nalei.com.br/unioes-homoafetivas-e-a-lei-maria-da-penha-230/<>. Acessado em: 14 de Julho de 2013.

SAFFIOTI, H. Gênero, Patriarcado e Violência. São Paulo:Editora Fundação Perseu Abramo, 2004. 
SANTIN, V. F. Igualdade Constitucional na Violência Doméstica. Disponível em: <>http://www.apmp.com.br/juridico/santin<>. Acessado em: 14 de Julho de 2013.

SILVA JÚNIOR, E. M. Lei 11.340/2006: Violência doméstica contra a mulher. Revista Jus Navagani. Disponível em: <>http://jus.com.br/revista/texto/9144/direito-penal-de-genero<>. Acessado em: 14 de Julho de 2013.

SWAIN, T. N. Para além do binário: Os queers e o heterogênero. Revista Gênero. v. 2, n.1, 2001. pag. 87-98.

TORRÃO FILHO, A. Uma questão de gênero: onde o masculino e o feminino se cruzam. Cadernos Pagu, v. 24, n.1, 2005, p. 127-152. 